\title{
Infant Mortality
}

National Cancer Institute

\section{Source}

National Cancer Institute. Infant Mortality. NCI Thesaurus. Code C16729.

Any disease or condition resulting in postnatal death before age $1 \mathrm{yr}$. $(\mathrm{NCl})$ 